\title{
Syagrus romanzoffiana: Queen Palm ${ }^{1}$
}

\author{
Timothy K. Broschat ${ }^{2}$
}

The queen palm is a popular feather-leaved palm with graceful arching leaves (Fig. 1). It is one of the hardiest of the tropical-looking palms, being suitable for planting in USDA plant hardiness zone $9 \mathrm{~B}\left(>25^{\circ} \mathrm{F}\right)$. Queen palms are considered to be moderately tolerant of salt spray. They can reach heights up to $50 \mathrm{ft}$ with a spread of $20-25 \mathrm{ft}$. The smooth gray trunk varies from $8-15$ inches in diameter, depending on the seed source and environment, and may contain bulges. Large inflorescences of cream-colored flowers are produced from within the leaves in the canopy during spring and summer months. These are followed by

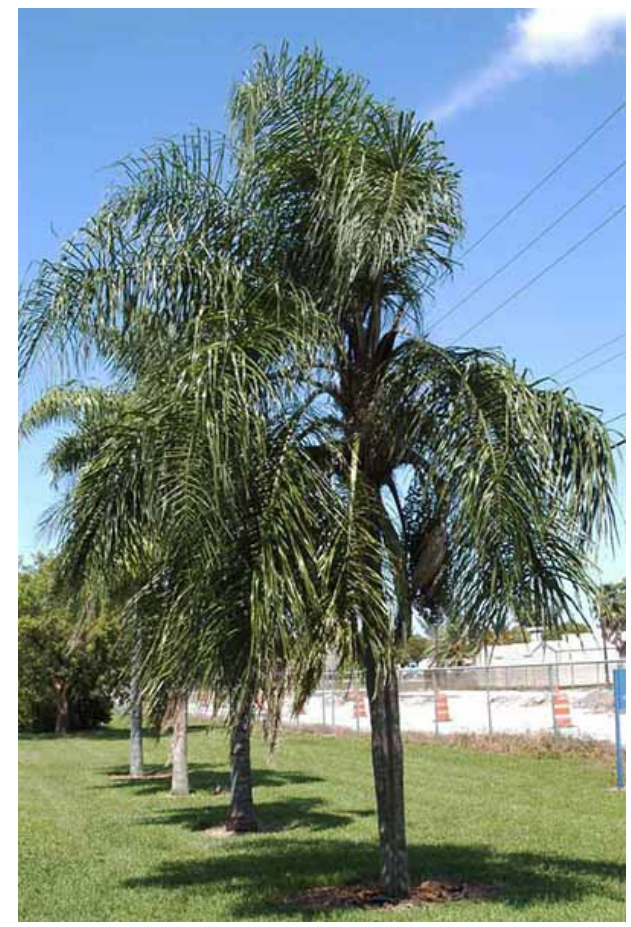

Figure 1. Queen palm, Syagrus romanzoffiana.

Credits: T. K. Broschat bright orange, round to slightly elongated fruits between $3 / 4$ and 1 inch long (Fig. 2). Fruit drop is a major concern for queen palms because fruit clusters can weigh over 100 pounds and contain over a thousand seeds. These accumulate on the ground beneath the canopy, where some will sprout into unwanted seedlings (Fig. 3).

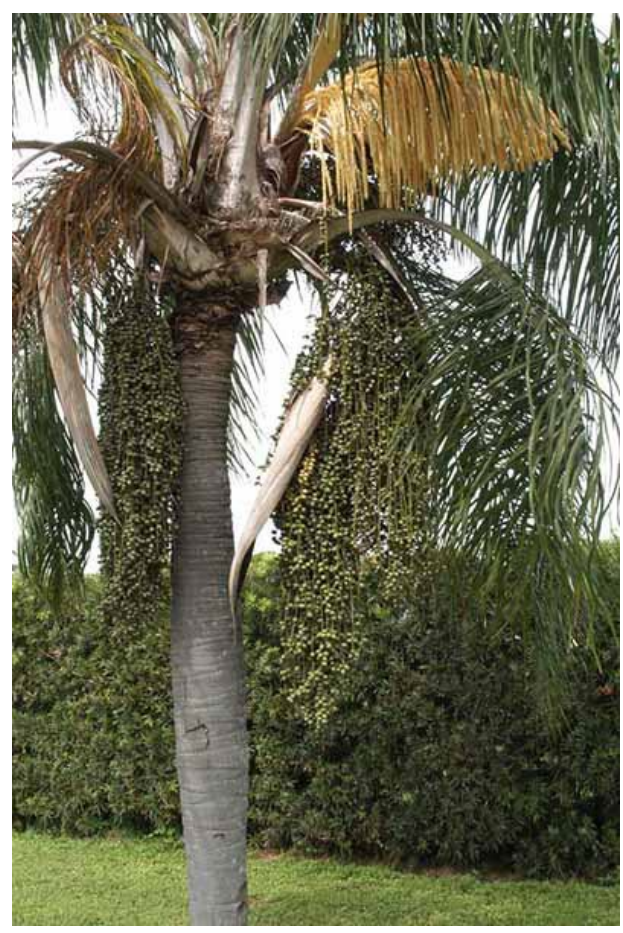

Figure 2. Inflorescence and immature fruit stalk on queen palm. Credits: T. K. Broschat

1. This document is ENH-767, one of a series of the Environmental Horticulture, UF/IFAS Extension. Original publication date November 1993. Revised April 2007, February 2013 and October 2013. Visit the EDIS website at http://edis.ifas.ufl.edu.

2. Timothy K. Broschat, professor, Environmental Horticulture Department, UF/IFAS Fort Lauderdale Research and Education Center, Davie, FL 33314. 


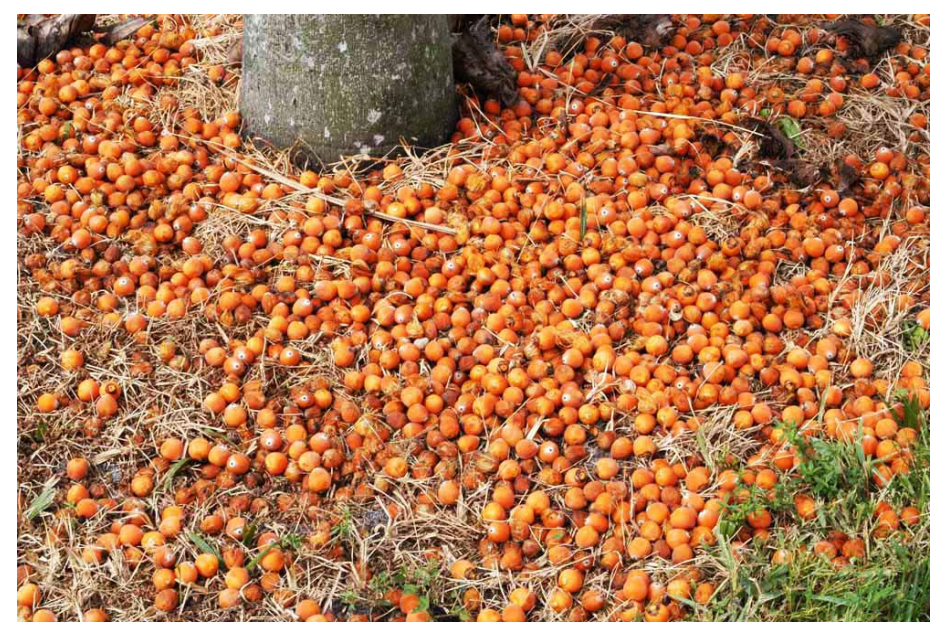

Figure 3. Fallen ripe fruit of queen palm.

Credits: T. K. Broschat

Queen palm seeds to be used for propagation should be half ripe to fully ripe with the fruit pulp removed. Soaking the cleaned seeds in water for two days prior to planting in a well-drained, but uniformly moist potting soil can improve germination in this species. Queen palm seed germinates slowly and erratically, taking from six weeks to six months. As with most palm species, high temperatures $\left(90-95^{\circ} \mathrm{F}\right)$ are required for seed germination. For more information about germinating palm seeds see "Palm Seed Germination" (EDIS EP238).

Queen palms are not considered to be self-cleaning, so every leaf must be manually cut off after it dies. The flower and fruit stalks are typically removed at the time that dead leaves are removed to reduce the mess caused by falling fruit. Avoid removing leaves that are not completely dead because these leaves serve as a supplementary source of potassium $(\mathrm{K})$ in the absence of sufficient $\mathrm{K}$ in the soil.

Most queen palms in southeastern United States exhibit some degree of $\mathrm{K}$ deficiency, which in its mildest stages causes small, translucent, yellow-orange spotting on the oldest leaves. As the deficiency becomes more severe, the tips of leaflets towards the ends of the oldest leaves become necrotic and frizzled (curled) (Fig. 4). This eventually causes premature death of the oldest leaves and reduces the number of leaves that the palm can support. In severe cases, all of the leaves in the canopy will be affected and even new leaves will emerge chlorotic, reduced in size, and frizzled. If untreated, severe $\mathrm{K}$ deficiency can be fatal to palms. For more information about pruning palms and $\mathrm{K}$ deficiency in palms, see "Pruning Palms" (EDIS EP443) and "Potassium Deficiency in Palms" (EDIS EP269).

While frizzling of the leaflets at the ends of the oldest leaves is indicative of $\mathrm{K}$ deficiency, frizzling of the leaflets at the

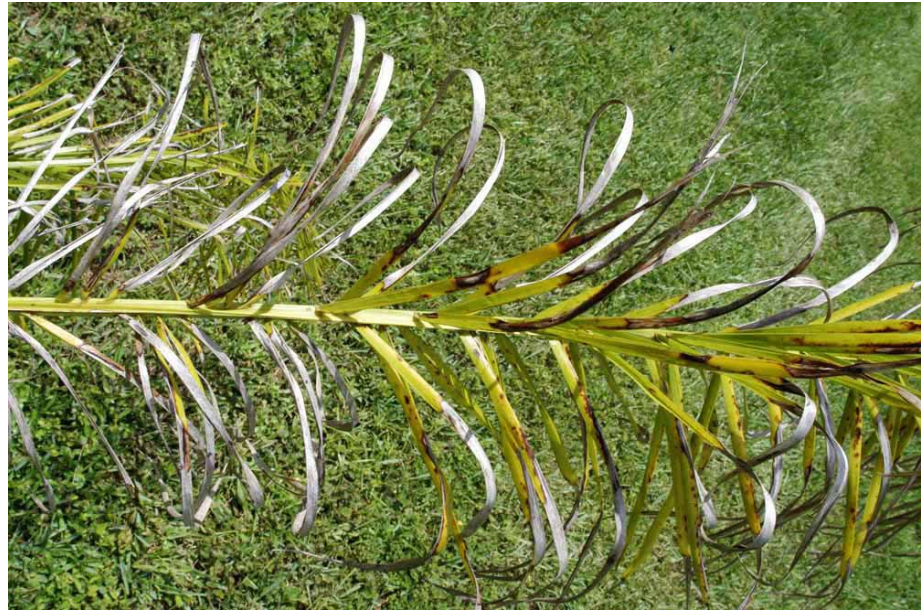

Figure 4. Potassium deficient older leaf of a young queen palm. Credits: T. K. Broschat

base of the youngest leaves is caused by manganese $(\mathrm{Mn})$ deficiency (Fig 5). If young leaves of frizzled queen palms are examined more closely, longitudinal necrotic streaking will typically be observed on otherwise chlorotic leaflets. The position of the frizzling (base vs. tip of the leaf) plus the presence of necrotic streaking helps distinguish $\mathrm{Mn}$ deficiency from severe $\mathrm{K}$ deficiency, which from a distance appear identical. It is not unusual to see both $\mathrm{Mn}$ and $\mathrm{K}$ deficiencies on the same palm or even on the same leaf if the $\mathrm{K}$ deficiency is severe enough. For more information about Mn deficiency, see "Manganese Deficiency in Palms" (EDIS EP267).

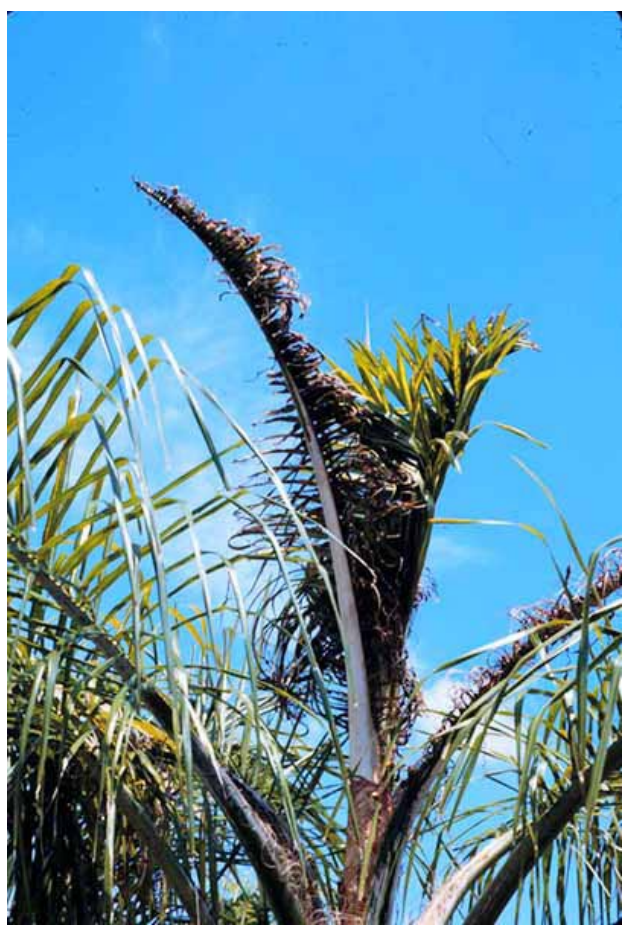

Figure 5. Manganese deficiency on queen palm. Credits: T. K. Broschat 
On alkaline soils, queen palms may also exhibit uniformly yellow (chlorotic) new leaves. This is typically caused by iron $(\mathrm{Fe})$ deficiency. They may also show various leaf distortions on otherwise dark green new leaves that are caused by boron (B) deficiency. Boron deficiency can cause puckering, crumpling, truncation, incomplete opening, twisting, or stunting of the new leaves, or it may cause the palm to branch or grow sideways or even downwards (Figs 6-8). Since the availability of micronutrients such as $\mathrm{Mn}, \mathrm{B}$, or Fe to plants decreases sharply with increasing soil $\mathrm{pH}$, queen palms generally grow poorly on alkaline soils. For more information about Fe or B deficiencies in palms, see "Iron Deficiency in Palms" (EDIS EP265) and "Boron Deficiency in Palms" (EDIS EP264).

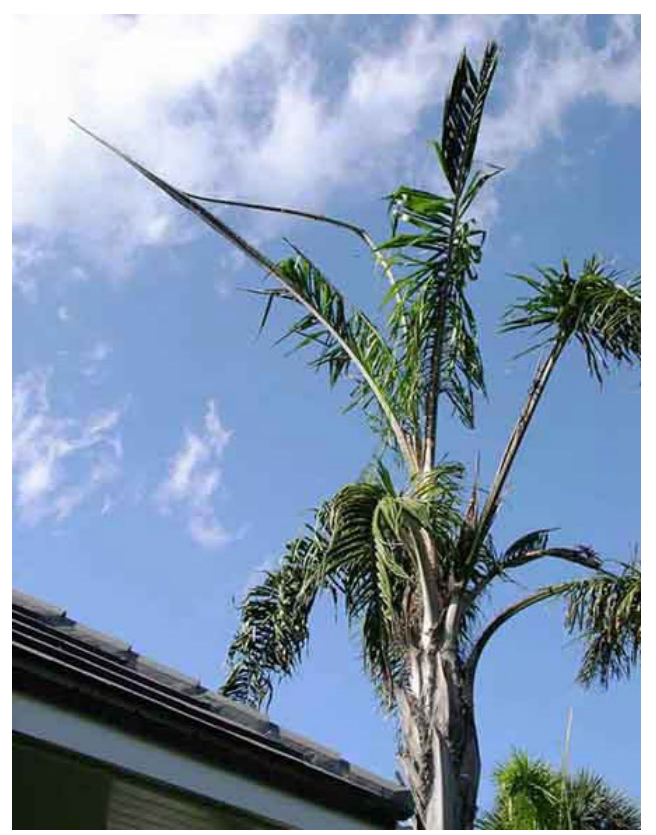

Figure: 6 . Incompletely opened spear leaves in queen palm caused by boron deficiency.

Credits: T. K. Broschat

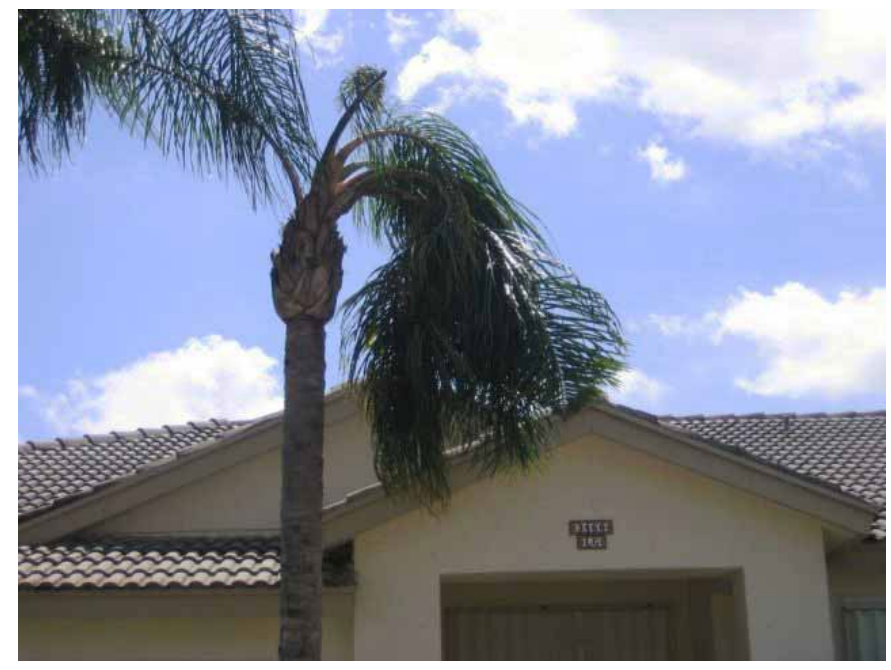

Figure 7. Stunted new leaf and sideways growth of queen palm caused by boron deficiency.

Credits: T. K. Broschat

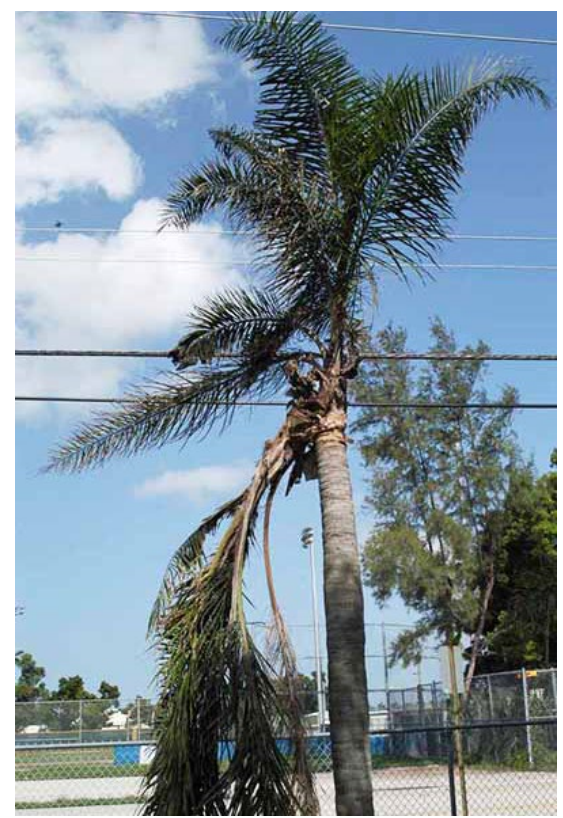

Figure 8. Branching and downward growth in queen palm caused by boron deficiency.

Credits: T. K. Broschat

Since most queen palms in the landscape are deficient in one or more nutrient deficiencies, regular application of an $8-2-12+4 \mathrm{Mg}$ palm fertilizer that has $100 \%$ of its $\mathrm{N}, \mathrm{K}$, and $\mathrm{Mg}$ in controlled-release form is recommended for queen palms in the southeastern United States. For more information about landscape palm fertilization see "Fertilization of Field-grown and Landscape Palms in Florida” (EDIS EP261).

Queen palms in the landscape are susceptible to several lethal diseases. Ganoderma butt rot, caused by Ganoderma zonatum, causes an internal discoloration and decay of the trunk (Fig. 9). This is generally confined to the bottom 3-4 feet of the trunk, and, once about $85 \%$ of the cross sectional area of the trunk has been destroyed by the fungus, the canopy may show signs of wilting or other water stress symptoms, followed by fairly rapid loss of lower leaves, and, eventually, death of the palm (Fig. 10). Fungal fruiting bodies called conks may emerge from the lower portion of the trunk prior to death of the palm. Initially they look like hard marshmallows, but eventually they become woody, shelf-like structures with a brown top and white bottom (Fig. 11). These conks can produce billions of reddish-brown dust-like spores that will blow everywhere, spreading the disease. Thus, while there is no control for this disease, removing conks in the early stages of their development can reduce the rate of spread of this disease. Be sure to remove or grind the stump after cutting down any palm to prevent Ganoderma conks from growing and reproducing on the stump. For more information about this disease, see "Ganoderma Butt Rot of Palm” (EDIS PP100). 


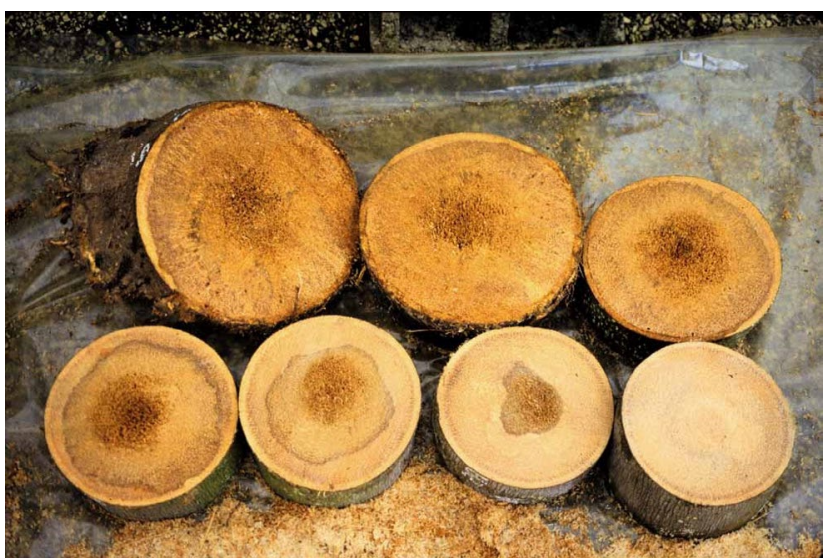

Figure 9. A series of cross sections through the lower trunk of a queen palm infected with Ganoderma zonatum. Note that the diameter of the internal discoloration decreases as the height above the ground increases.

Credits: T. K. Broschat

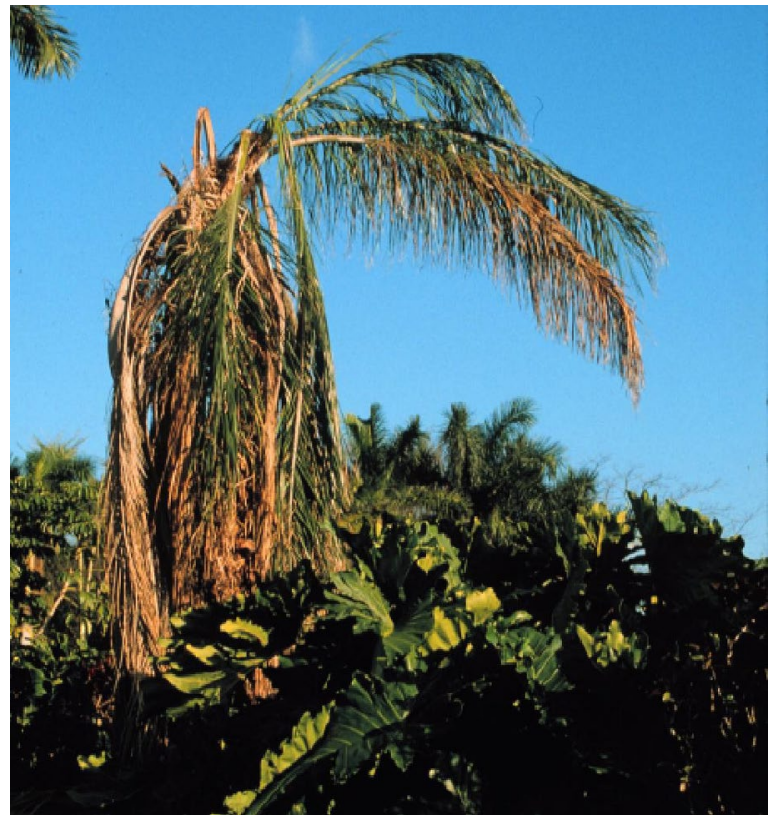

Figure 10. Wilted crown of queen palm infected with Ganoderma zonatum.

Credits: T. K. Broschat

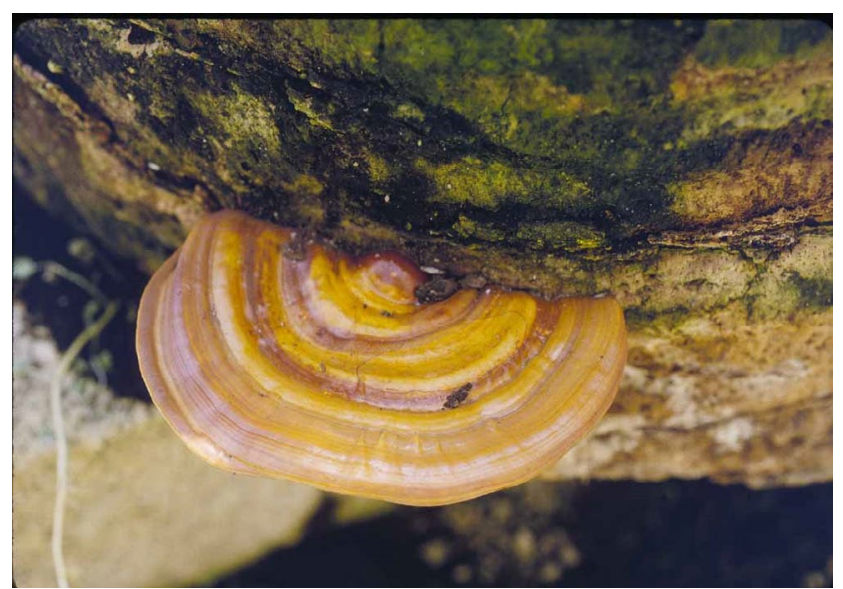

Figure 11. Conk or fungal fruiting body of Ganoderma zonatum. Credits: M. L. Elliott
Another fungus, Thielaviopsis paradoxa, also causes a trunk rot of queen palms, but this one is largely confined to the softer upper parts of the trunk, often just below the crown. This fungus requires a wound in the trunk to become established. Such wounds are often caused by rough handling during transplanting or pruning, including pulling off dead leaves or leaf bases that are still firmly attached to the trunk. Once established, this disease causes a soft rot of the trunk that may be visible from the outside as a watersoaked, often bleeding, or soft sunken area on the trunk. Once a majority of the trunk cross-sectional area has been rotted, the crown may wilt or simply topple over with no warning (Fig. 12). There is no control for this disease, but it can easily be prevented by avoiding trunk wounding when pruning or transplanting. For more information about this disease, see "Thielaviopsis Trunk Rot of Palms" (EDIS PP143).

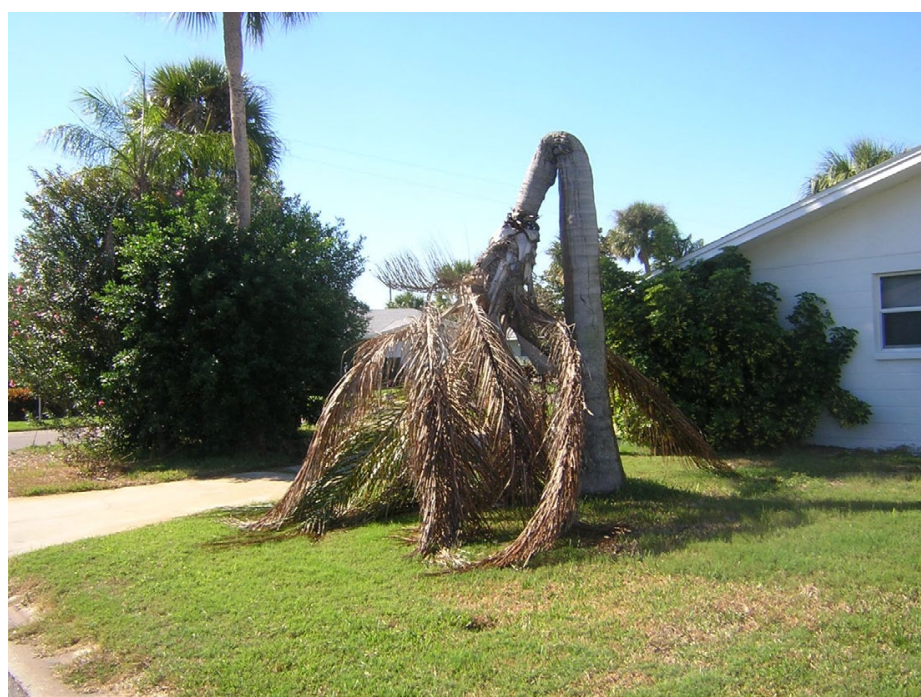

Figure 12. Toppled crown of queen palm caused by Thielaviopsis trunk rot.

Credits: M. L. Elliott

A more recent disease on queen palms is Fusarium wilt, caused by Fusarium oxysporum f. sp. palmarum. It infects the petioles of the oldest leaves, causing a characteristic reddish-brown longitudinal stripe on one side of the petiole and rachis. The leaflets on that side of the rachis quickly die, while leaflets on the other side remain green for a while (Fig. 13). Eventually, the entire leaf dies, and this process is rapidly repeated on successively younger leaves until the entire crown is dead. These dead leaves remain in place for a while, giving the palm a "freeze-dried" look (Fig. 14). There is no control for this disease. Although it is believed to be spread primarily by wind-blown spores, it is likely also spread via contaminated pruning tools, moving it from infected to healthy trees. For more information about this 
disease, see "Fusarium Wilt of Queen and Mexican Fan Palms” (EDIS PP278).

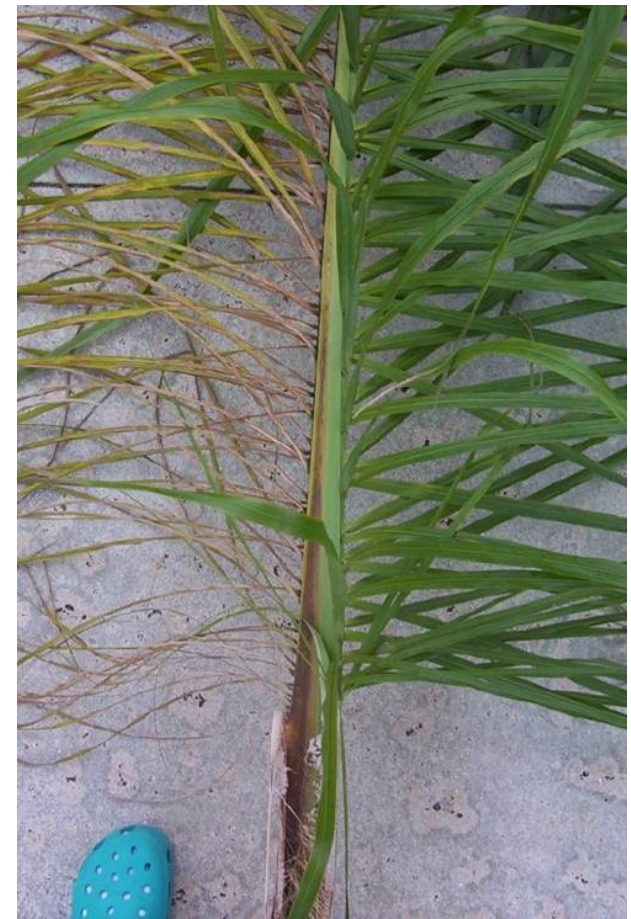

Figure 13. Reddish-brown petiole and rachis stripe of queen palm caused by Fusarium wilt. Note that leaflets on affected side are necrotic.

Credits: M. L. Elliott

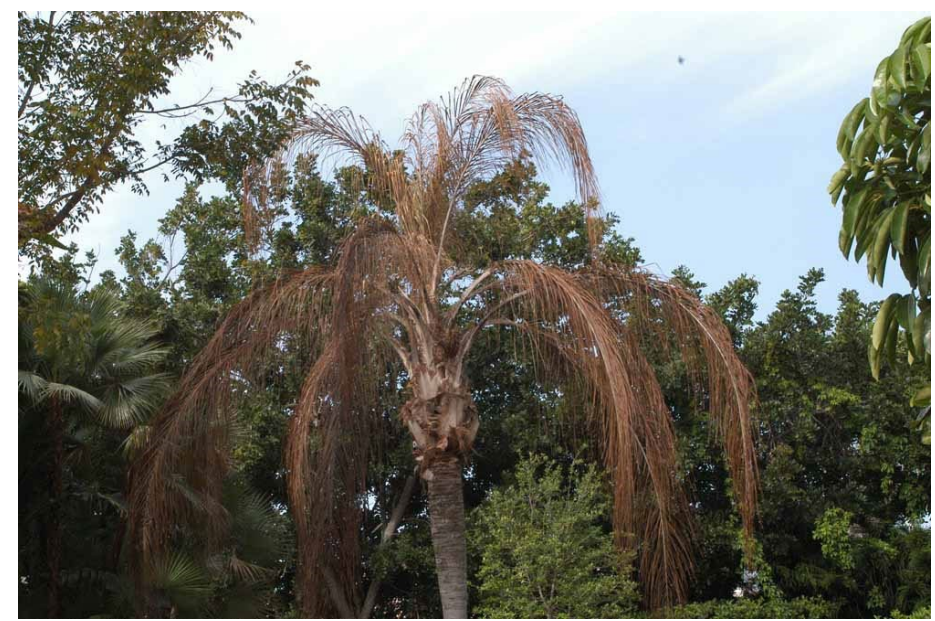

Figure 14. Freeze-dried appearance of queen palm killed by Fusarium wilt.

Credits: M. L. Elliott

\section{Additional References}

Broschat, T. K. 2007. "Boron deficiency symptoms in palms." Palms 51: 115-126.

Broschat, T. K. 2007. "Boron deficiency, phenoxy herbicides, stem bending, and branching in palms-is there a connection?" Palms 51:161-163.

Broschat, T. K. and H. Donselman. 1987. "Effects of fruit maturity, storage, presoaking, and seed cleaning on germination in three species of palms." J. Environ. Hort. 5:6-9.

Elliott, M. L., T. K. Broschat, J. Y. Uchida, and G. W. Simone. 2004. "Compendium of ornamental palm diseases and disorders.” Amer. Phytopath. Soc., St. Paul, MN

Elliott, M. L., E. A. DesJardin, K. O’Donnell, D. M. Geiser, N. A. Harrison, and T. K. Broschat. 2010. "Fusarium oxysporum f. sp. palmarum, a novel forma specialis causing a lethal disease of Syagrus romanzoffiana and Washingtonia robusta in Florida." Plant Disease 94:31-38. 